\title{
Why the Binding Theory Doesn't Apply at $\mathrm{LF}^{*}$ \\ Glyn Hicks
}

Please note: This is a prepublication version. The full reference is: Hicks, Glyn (2008). Why the binding theory doesn't apply at LF. Syntax 11(3), 255-280. To cite this article, please use the published article at: http://www3.interscience.wiley.com/journal/118498442/home.

Abstract. This article argues that the relegation of the binding theory to the C-I interface (LF) is theoretically undesirable and empirically unwarranted. Recent Minimalist research has sought to eliminate the binding theory from UG by reducing its conditions to narrow-syntactic operations (Hornstein 2000, 2006; Reuland 2001, 2006; Kayne 2002; Zwart 2002, 2006; Hicks 2006). This approach remains controversial since the canonical Minimalist binding theory (Chomsky 1993; Chomsky and Lasnik 1993) views the binding conditions as interpretive rules applying at LF, supported by evidence that Condition A interacts with other interpretive phenomena assumed to be determined at LF (Lebeaux 1998; Fox and Nissenbaum 2004). While the interaction of anaphor binding and scope relations in particular is not disputed, I show that it is attributable to factors outside the binding theory, namely the requirement that variables (including anaphors) must be c-commanded by their binders at LF. Deprived of its strongest empirical argument, the LF binding theory can then be picked apart.

*This article grew out of a paper presented at the Binding Theory and Reflexivity Workshop at the University of Stuttgart, organised by Jonny Butler in October 2005. Many thanks to him for inviting me, and also for numerous conversations we've had over the last few years on binding and related topics. Thanks also to David Adger, Kook-Hee Gill, Norbert Hornstein, Bernadette Plunkett, Ken Safir, George Tsoulas, Tohru Uchiumi, and Jan-Wouter Zwart for enlightening, encouraging, and entertaining comments and criticism. Particular thanks also to the two anonymous Syntax reviewers. A version of this article is due to appear as chapter 3 of The Derivation of Anaphoric Relations (John Benjamins), a forthcoming book based my PhD thesis (Hicks 2006). This research was undertaken with the support of the AHRC, award number 2004/107606. 


\section{Introduction}

Since the earliest generative approaches to binding, one of the most enduring controversies has been the level(s) of representation where the binding theory should apply. While work in the Government and Binding framework suggested that the binding theory might require reference to D-structure, S-structure, and LF (e.g. Belletti and Rizzi 1988), this position is made untenable by Chomsky's (1993) Minimalist elimination of D-structure and S-structure. Consequently, the binding theory is relegated to the C-I interface (LF), which sits somewhat uncomfortably with the fact that binding exhibits properties typical of syntactic phenomena. Hence, recent attempts have been made to bring the binding theory back from the C-I interface (e.g. Epstein, Groat, Kawashima, and Kitahara 1998; Hornstein 2000, 2006; Reuland 2001, 2006; Kayne 2002; Zwart 2002, 2006; Hicks 2006), with the welcome result that the binding conditions may then be reduced to narrow syntactic operations such as Merge, Move, and Agree.

However, the Minimalist literature also provides apparently compelling evidence for the binding theory applying at LF, as Condition $\mathrm{A}$ is shown to interact with other interpretive phenomena assumed to hold at LF, namely quantifier (scope) interpretation, idiom interpretation, and bound variable interpretation (Chomsky 1993; Lebeaux 1998; Fox and Nissenbaum 2004; Sportiche 2006). This has been argued to show that these phenomena share a common input with Condition A, i.e. a single LF representation. Treating each type of interaction individually, this article reveals that such a conclusion may be premature. In particular, it is not Condition A that holds at LF, but rather an independent requirement that bound variables (including anaphors) must be c-commanded by their binders. The narrow-syntactic and interface approaches to Condition A make different empirical predictions with respect to the point in the derivation at which local c-command must hold between the antecedent and anaphor. 


\section{Evidence for a narrow-syntactic binding theory}

\subsection{Theoretical arguments}

An approach which views the binding theory as a set of constraints applying at LF raises concern under Minimalist assumptions. Crucially, Minimalism must seek to explain why-rather than simply stipulate that-binding facts are the way they are. The Government and Binding framework was able to pin down a reasonably successful account of the locality constraints on binding through the definition of the 'Governing Category' (Chomsky 1981, 1986). In the spirit of that approach, we can only realistically hope to find an explanation for why binding domains look the way they do if they are in some way related to the constraints governing movement. Indeed, the classical binding theory has envisaged a single explanation for the common properties of binding and movement (e.g. c-commanding antecedents of anaphors/traces, locality constraints) since Chomsky 1973. Chomsky (1993); Chomsky and Lasnik (1993), however, abandon one of the major insights of generative syntax, and with it, all serious hope of explaining binding domains. Since movement must be considered a narrow-syntactic process, in the absence of evidence to the contrary, it is natural to assume that binding is too: for example, a narrow-syntactic approach to binding lets us make the strong claim that locality effects are uniquely determined by syntactic factors, and not by properties of the interfaces. In light of the fact that locality in both movement and binding is quite similarly constrained, an LF binding theory would involve a conspicuous redundancy in that very similar locality constraints would have to apply in narrow syntax (for movement) and at LF (for binding). This would surely be a glaring weakness in any Minimalist theory; (the effects of) the local binding conditions must therefore be determined in narrow syntax.

An ambitious but fruitful strategy in seeking an explanation for binding facts (rather than simply aiming for empirical coverage) is to derive a theory of binding purely from principles independently required in the framework. Recently, significant steps have been made towards reducing the binding conditions to narrow-syntactic operations. The analyses of Horn-

stein 2000, 2006; Reuland 2001, 2006; Kayne 2002; Zwart 2002; Hicks 2006 outline different 
but related methods of explaining all of the central elements of the binding theory-including c-command, local binding domains, and the encoding of referential dependencies-within narrow syntax. Moreover, each of these shows that the properties of binding follow from one or more of the narrow-syntactic operations of Merge, Move, and Agree. The reader is invited to review the above works for further theoretical arguments for a narrow-syntactic binding theory. This article concentrates largely on empirical evidence, since this is the evidence on which the argument for the binding theory at LF is most strongly defended. At any rate, we will see that even the empirical evidence alone is sufficient to demonstrate that the binding theory does not apply at LF.

\subsection{Empirical evidence for a syntactic Condition B}

As noted by Reuland (2001), a syntactic approach to the binding theory will generally be better equipped to capture crosslinguistic variation in binding, since interface properties are, by assumption, universal. We can support this kind of theoretical argument with empirical data, showing either that processes assumed to apply at LF do not interact with Condition B effects in the predicted manner, or that factors which cannot be relevant at LF are capable of influencing the interpretation of pronouns.

\subsubsection{Locality in Condition B domains does not hold at LF}

Evidence from A-movement constructions could be used against Condition B applying at LF. It has been argued by Chomsky (1995b: 327) that A-movement does not reconstruct (see, e.g., Lasnik 1999 for a summary of the arguments for this approach). ${ }^{1}$ Chomsky provides (1) as evidence:

(1) $* \mathrm{John}_{\mathrm{i}}$ expected [TP him $\mathrm{i}$ to seem to me $\left[\mathrm{TP}<\mathrm{him}_{\mathrm{i}}>\right.$ to be intelligent]]

\footnotetext{
${ }^{1}$ Lasnik (1999) proposes that A-movement and $\mathrm{A}^{\prime}$-movement are underlyingly different in that A-movement does not leave a trace/copy. Boeckx (2001: 508, fn.2) highlights that Epstein and Seely (1999) reach a similar conclusion and that Fox (1999) argues alternatively that A-movement leaves a simple trace, not a true copy.
} 
If reconstruction were allowed to apply to the raised pronoun in (1), effectively 'undoing' the narrow-syntactic movement, a version of Condition B that applies at LF would be incorrectly satisfied, since the unpronounced copy in the infinitival complement of seem would not then be in a local configuration with the antecedent John. ${ }^{2}$ Yet Wurmbrand and Bobaljik (1999) show that if the satisfaction of Condition B depends on the choice of a single position in a movement chain at LF, reconstruction would in fact be forced in other A-movement constructions in order to predict the attested Condition B effect.

(2) $* \mathrm{John}_{\mathrm{i}}$ seems to me [TP $<\mathrm{John}_{\mathrm{i}}>$ to be expected $\left[\mathrm{TP}<\mathrm{John}_{\mathrm{i}}>\right.$ to like $\left.\left.\mathrm{him}_{\mathrm{i}}\right]\right]$

Unless the copy of John in the deepest embedded vP (also containing the pronoun) is interpreted, Condition B is not violated at LF, since John and the pronoun are not, then, in a local configuration. However, as Wurmbrand and Bobaljik concede, this argument depends on the assumption of 'LF-coherence': the principle that any (e.g. moved) element occupies only one position in the LF representation. It could be counter-argued that the theoretical problem for the LF-approach to Condition B can be circumvented by assuming all parts of a movement chain are present at LF. If so, even without reconstruction, (2) would violate Condition B. In essence, such an approach to LF representations could allow an LF binding theory to correctly predict that moved pronouns must be locally free from their antecedent at all points during narrow syntax.

\footnotetext{
${ }^{2}$ Although Chomsky (1995b) does not specify what the binding domain for the pronoun is in (1), we may assume that it is the infinitival TP complement of seem. The important point is that the binding domain does not extend as far as the matrix clause subject. If it did, it would predict that the experiencer of the raising verb—in fact closer to the pronoun than the overt copy of John-should be able to induce the same sort of Condition B effect, contrary to fact:

(i) John seems to Mary [ $_{\mathrm{TP}}<\mathrm{John}>$ to be expected [TP $<$ John $>$ to like her $\left.\mathrm{j}_{\mathrm{j}}\right]$

Note that it is widely agreed that the experiencer (Mary) c-commands into the raising infinitival clause for the purposes of binding and so would potentially be capable of inducing Condition B effects with a pronoun within the infinitival clause, if it were sufficiently local.
} 


\subsubsection{Phonological factors can affect Condition B domains}

In light of the possible circumvention, we seek data which are less dependent on particular theories of LF. If LF representations were indeed permitted to contain information concerning each of the movement steps in the derivation, we could look to other kinds of information widely assumed to be absent from LF representations to see if they can be critical in determining Condition B effects. This would be in principle unexplainable if LF representations were taken to be the input to Condition B. The first possible example of this is one observed by Fiengo and Higginbotham (1981). A particularly well-known (but in many ways, problematic) piece of binding data is that pronouns embedded in 'picture noun phrases' (henceforth 'picture-DPs') which do not themselves contain an agentive or possessive subject can often be bound by the closest subject:

\section{(3) $\% \mathrm{John}_{\mathrm{i}}$ read [DP books about him $\mathrm{i}$ ]}

However, Fiengo and Higginbotham (1981) report that the judgment for (3) and similar sentences is rather variable across speakers, a fact also conceded by Chomsky (1982: 99, fn.24). They leave the grammaticality judgment open, which I indicate by $\%$ in (3). Fiengo and Higginbotham show that the stress assigned to the pronoun is critical for Condition B. Heavily stressing the pronoun removes the variation, with the sentence grammatical on the bound reading for the majority of speakers:

(4) $\mathrm{John}_{\mathrm{i}}$ read [DP books about $\left.\mathrm{HIM}_{\mathrm{i}}\right]$

(Fiengo and Higginbotham 1981)

Equally importantly, for many speakers, Fiengo and Higginbotham report that the grammaticality of (4) is in robust contrast to (5), where the pronoun is unstressed and reduced to ' $\mathrm{im}^{3}$

(5) * $\mathrm{John}_{\mathrm{i}}$ read [DP books about $\left.{ }^{\prime} \mathrm{im}_{\mathrm{i}}\right]$

(Fiengo and Higginbotham 1981)

\footnotetext{
${ }^{3}$ As noted above, binding judgements into picture-DPs generally seem to paint an unclear picture. My own judgement is that (5) is not especially ungrammatical.
} 
The reason for the attested variation in sentences such as (3) may be that the prosodic contour is not indicated: speakers might simply be judging different sentences. Regardless of this, (4) and (5) appear to show that, at least for many speakers, a phonological factor influences whether or not the picture-DP constitutes a local binding domain for the pronoun inside it. However, a possible objection is that the effect is not due to phonological stress per se, but due to a related semantic effect, like focus: the pronoun is focussed in (4), but not (3). On the assumption that focus is encoded in LF representations, if Condition B were to apply at LF the contrast between (4) and (5) for many speakers could be (at least in principle) explained by an interaction of focus with Condition B.

Remaining with picture-DPs for the moment, Fiengo and Higginbotham (1981) also suggest that the specificity of a picture-DP determines whether the picture-DP constitues a local domain for Condition B. They observe a contrast between the ungrammatical (5) and an equivalent sentence with a demonstrative determiner:

(6) $\mathrm{John}_{\mathrm{i}}$ read [DP that book about ' $\left.\mathrm{im}_{\mathrm{i}}\right]$ (Fiengo and Higginbotham 1981)

However, it may not be the specificity of the determiner which is the crucial factor. Hestvik (1990) reports a contrast (at least to some degree for many speakers) between the ungrammatical (7a) and the grammatical $(7 b):^{4}$

(7) a. $\% \mathrm{John}_{\mathrm{i}}$ saw a picture of him $_{\mathrm{i}}$

b. $\mathrm{John}_{\mathrm{i}}$ saw some pictures of himi

Nor can the number distinction between (7a) and (7b) be the source of the contrast, since when a null indefinite plural determiner is employed, the Condition B data pattern with the singular picture-DP in (7a) rather than the plural one in (7b):

\footnotetext{
${ }^{4}$ Given the observations above concerning the stress assigned to the pronouns themselves in these constructions, we will assume that the pronoun receives neutral stress. On this prosody I do not find (7a) ungrammatical, though it is somewhat worse when the pronoun is reduced to 'im, consistent with the observations of Fiengo and Higginbotham reported above.
} 
Hestvik observes a similar pattern in Norwegian. The Norwegian simplex expression (SE) reflexive seg is capable of inducing a Condition B effect if bound too locally. (9a) is thus ruled out in much the same manner as the non-reflexive pronoun is ruled out in (9b):

(9) a. * Jon $_{\mathrm{i}}$ snakket om $\operatorname{seg}_{\mathrm{i}}$

$\mathrm{John}_{\mathrm{i}}$ talked about $\mathrm{SE}_{\mathrm{i}}$

b. ?*Vi fortalte $\mathrm{Jon}_{\mathrm{i}}$ om ham $_{\mathrm{i}}$

We told $\mathrm{John}_{\mathrm{i}}$ about himi

(Norwegian)

Returning now to Hestvik's 'specificity' contrast in Condition B effects, take the following Norwegian sentences.

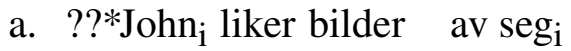

$\mathrm{John}_{\mathrm{i}}$ likes pictures of $\mathrm{SE}_{\mathrm{i}}$

b. ??*John ${ }_{i}$ fant et bilde av seg ${ }_{i}$

$\mathrm{John}_{\mathrm{i}}$ found a picture of $\mathrm{SE}_{\mathrm{i}}$

c. $\mathrm{John}_{\mathrm{i}}$ liker disse bildene av $\mathrm{seg}_{\mathrm{i}}$

$\mathrm{John}_{\mathrm{i}}$ likes these pictures of $\mathrm{SE}_{\mathrm{i}}$

'John likes these pictures of him(self)'

(Norwegian; Hestvik 1990)

The Condition B effect in the English (7a) and (8) for some speakers is reflected in the Norwegian (10a) and (10b) respectively, while when a demonstrative is used in both (6) and (10c) the Condition B effect is obviated. If, though, as the contrast between (7a) and (7b) suggests for English, it is not specificity that is at stake, it may be some other property of DPs headed by $a$ or a null determiner that accounts for why they fail to create Condition B domains. Furthermore, Hestvik (1990: 78, fn.20) notes that some speakers find (10b) grammatical, reinforcing the view that specificity is not necessarily the crucial factor. It is not unreasonable to speculate that the phonological 'lightness' of these determiners coincides with the failure of the DPs that they head to constitute a local binding domain. We could then suggest that for the speakers who judge (10b) grammatical, the improved acceptability over (10a) could be because an overt de- 
terminer et ('a') ensures that the DP is a still 'heavier' phonological domain and so is somehow capable of constituting a Condition B domain, just as in (10c) with a (phonologically heavier) demonstrative.

While grammaticality judgments of bound pronouns in picture-DPs are somewhat variable across speakers, further evidence that the phonological 'weight' of a constituent has some effect in determining its behaviour as a binding domain can be found in Norwegian. Recall that in Norwegian both pronouns and the SE reflexive seg induce Condition B effects. Hellan (1988) notes that Condition B effects attested with both non-reflexive pronouns and the SE reflexive disappear when the constituent containing them is made phonologically heavier. For example, compare (9a) with (11a) and (9b) with (11b): ${ }^{5}$

(11) a. $\mathrm{Jon}_{\mathrm{i}}$ snakket om $\mathrm{seg}_{\mathrm{i}}$ og sine $_{\mathrm{i}}$ gjerninger $\mathrm{John}_{\mathrm{i}}$ talked about $\mathrm{SE}_{\mathrm{i}}$ and $\mathrm{SE}$ 's $_{\mathrm{i}}$ deeds

'John talked about himself and his deeds.'

b. Vi fortalte $\mathrm{Jon}_{\mathrm{i}}$ om ham $_{\mathrm{i}}$ og hans $\mathrm{k}_{\mathrm{i}}$ kusine

We told John about himi $_{\mathrm{i}}$ and his $\mathrm{i}_{\mathrm{i}}$ cousin

'We told John about himself and his cousin.'

(Norwegian; Hellan 1988)

Further data with the possessive reflexive sin support this view. (12a) is also assumed to be ruled out by Condition B, yet according to Hellan the same structural configuration gives rise to no Condition B effect when the DP is made heavier with additional lexical material, as in $(12 b)$ and (12c):

$$
\begin{aligned}
& \text { a. } \text { *on }_{\mathrm{i}} \text { er } \sin _{\mathrm{i}} \quad \text { fiende } \\
& \mathrm{John}_{\mathrm{i}} \text { is } \mathrm{SE}_{\mathrm{i}} \text {.POSS enemy REFL self } \\
& \text { b. } \mathrm{Jon}_{\mathrm{i}} \text { er } \sin _{\mathrm{i}} \quad \text { egen fiende } \\
& \mathrm{John}_{\mathrm{i}} \text { is } \mathrm{SE}_{\mathrm{i}} \text {.POSS own enemy } \\
& \text { 'John is his own enemy.' }
\end{aligned}
$$

\footnotetext{
${ }^{5}$ The same effect appears to arise in English, too:

(i) $\quad * \mathrm{John}_{\mathrm{i}}$ talked about him $\mathrm{i}$

(ii) $\mathrm{John}_{\mathrm{i}}$ talked about him $\mathrm{i}_{\mathrm{i}}$ and his $\mathrm{i}_{\mathrm{i}}$ mother
} 


$$
\begin{aligned}
& \text { c. } \mathrm{Jon}_{\mathrm{i}} \text { er } \sin _{\mathrm{i}} \quad \text { aller verste fiende } \\
& \mathrm{John}_{\mathrm{i}} \text { is } \mathrm{SE}_{\mathrm{i}} \text {.POSS very worst enemy } \\
& \text { 'John is his very worst enemy.' }
\end{aligned}
$$

We can conclude that the source of both these contrasts and those found in the picture-DPs with different determiners is the phonological 'weight' of the constituent (in a sense which remains to be properly clarified, though this is not crucial for the purposes of this article). An LF binding theory could not successfully accommodate such data, since phonological properties are not encoded in LF-representations. ${ }^{6}$

\subsubsection{Case and inflectional features affect Condition B}

It is not simply phonological properties that are assumed to be absent in LF representations. In standard versions of Minimalism (Chomsky 1993 et seq.), it is assumed that certain morphosyntactic features are not interpreted (or interpretable) by LF. It follows (from the Full Interpretation principle) that LF representations cannot contain such features. For Chomsky, these include $[\phi]$ when not semantically interpreted (on T and $v$, for example) and [CASE]. Once we examine crosslinguistic data from other Germanic languages, it becomes apparent that these features interact with the possibility of bound readings for pronouns, a fact which is difficult to reconcile with an analysis of Condition B that applies at LF.

As outlined by Hoekstra (1994), Frisian has a 3rd person singular feminine pronoun har and a 3rd person plural pronoun har(ren). Both may be locally bound without inducing a Condition B effect (somewhat unusually for non-reflexive 3rd person pronouns):

a. $\mathrm{Hja}_{\mathrm{i}}$ skammen har(ren) $)_{\mathrm{i}}$ They $_{i}$ shamed them $i$

'They were ashamed of themselves.'

(Frisian; Hoekstra 1994)

b. Marie i wasket har $_{\mathrm{i}}$ Mary $_{i}$ washes her $i$

\footnotetext{
${ }^{6}$ In fact, it is also very difficult for a narrow-syntactic binding theory to explain why phonological properties may be relevant to Condition B. See Hicks (2006) for a narrow-syntactic reinterpretation of Condition B that is potentially capable of capturing such data.
} 
However, it is not the case that Condition B is simply not operative in Frisian, since this effect does not hold for other 3rd person pronouns:

a. $\mathrm{Hja}_{\mathrm{i}}$ skammen ${ }^{*} \mathrm{se}_{\mathrm{i}}$

They $_{\mathrm{i}}$ shamed *them ${ }_{\mathrm{i}}$

(Frisian; Hoekstra 1994)

b. Marie $_{\mathrm{i}}$ wasket $* \mathrm{se}_{\mathrm{i}}$

Mary $_{\mathrm{i}}$ washes *her

(Frisian; Reuland and Everaert 2001)

Hoekstra (1994) shows that the difference between har(ren) and se lies in their Case specification: se, which is assigned structural Case, gives rise to Condition B effects, while har(ren), which is assigned inherent Case, does not. Yet the requirement for a structural Case feature in order to be subject to Condition B could not be incorporated into a version of Condition B that applies at LF, since the relevant feature is not present in LF representations.

Case also plays a role in Condition B effects in Icelandic. In ECM constructions, Icelandic typically behaves like English in not permitting a pronominal ECM subject to be bound by the matrix subject:

$$
\begin{aligned}
& \text { María }_{\mathrm{i}} \text { taldi *hana } \\
& \text { Mary }_{\mathrm{i}} \text { believed } \text { *her }_{\mathrm{i}} \text { be gafaða }
\end{aligned}
$$

However, some Icelandic verbs assign a lexically selected oblique ('quirky') Case to their subjects, resulting in nominative Case assignment to their object or to the ECM subject. In contrast to (15), when the pronoun is an ECM subject assigned nominative Case, it can be bound by the quirky subject (Taraldsen 1996):

$$
\begin{aligned}
& \text { Maríu }_{\mathrm{i}} \text { fannst hún } \\
& \text { Mary }_{\mathrm{i}} \text {-DAT thought-3SG she } \mathrm{i}_{\mathrm{i}} \text {-NOM be gáfuð } \\
& \text { 'Mary thought she was gifted.' }
\end{aligned}
$$


The interaction between agreement inflections and Condition B effects in Icelandic provides us with a similar argument against an LF approach to Condition B. Since Icelandic quirky subjects do not trigger agreement with their verbs, the verbal morphology either consists of a default 3rd person singular inflection, or is governed by the $\phi$-features of the nominative object (Thráinsson 1979). As highlighted by Taraldsen (1995) (following an observation due to Höskuldur Thráinsson), verbal morphology may be critical in determining whether the ECM subject induces a Condition B violation when bound by the matrix subject:

a. Konunum $\mathrm{K}_{\mathrm{i}}$ fundust $* \mathrm{pær}_{\mathrm{i}}$ vera gáfapar women-the ${ }_{i}$-DAT seemed-3PL $*$ they -NOM be gifted-FEM.PL-NOM 'The women thought they were smart.'

b. Konunum Kannst $_{i} \quad$ pær $_{i}$ vera gáfapar women-the $_{i}$-DAT seemed-3SG they ${ }_{i}$-NOM be gifted-FEM.PL-NOM 'The women thought they were smart.'

(Taraldsen 1995)

When the nominative ECM subject governs the verbal agreement, as in (17a), the bound interpretation is ruled out by Condition B; when default 3rd person singular morphology appears on the verb, the Condition B effect disappears, as in (17b). Thus, Condition B is again shown to be sensitive to morphosyntactic information (here, inflectional features) that is commonly assumed not to be accessible at LF. ${ }^{7}$

\section{Counter-evidence 1: trapping effects}

For the reasons outlined in section 2.1 above, I follow Hornstein (2000) in assuming that all else being equal, a syntactic approach to binding is preferred over the LF approach. While empirical

\footnotetext{
${ }^{7}$ Envisaging a binding theory that applies at LF, Taraldsen (1995) supposes that (17a) and (17b) involve different structural positions for the ECM subject at LF. He suggests that an agreeing ECM subject raises covertly to the Specifier of a Number Agreement head in the matrix clause. It is this covert movement which then brings the pronoun into a configuration in violation of Condition B. However, this explanation does not sit comfortably with more recent Minimalist assumptions. Agreement heads are commonly considered not not legitimate syntactic objects due to an absence of any interpretable features borne by them (Chomsky 1995b), and more recently, agreement is determined at long distance in probe-goal configurations (without movement) by the operation Agree (Chomsky 2000 et seq.).
} 
evidence from Condition B effects supports this view, to confirm that binding relations are determined in narrow syntax rather than at LF we must show that a narrow-syntactic version of Condition A fares at least as well as the LF approach in terms of its empirical coverage. The rest of this article teases apart and tests the predictions of the two competing approaches with respect to interactions between anaphor binding and other interpretive phenomena. This has proved a key battleground in the argument for where the binding theory applies, and the putative interactions are often taken as evidence that Condition A applies at LF. First I deal with cases where an anaphor embedded in a moved constituent is trapped in a 'high' position for the purposes of interpretation, due to other factors in the sentence; this is known as a "trapping effect'.

\subsection{Condition $C$ interacting with anaphor binding}

It is reported that trapping effects are observed in the interaction between Condition A and Condition $\mathrm{C}^{8}{ }^{8}$ sometimes adduced in favour of the conclusion that Condition A applies at LF. It is well known that Condition $\mathrm{C}$ displays different behaviour according to whether the relevant R-expression is embedded in an adjunct or a complement: ${ }^{9}$

(18) a. [Which argument [that $\mathrm{John}_{\mathrm{i}}$ made $]_{\mathrm{k}}$ did he $\mathrm{i}_{\mathrm{i}}$ believe $\mathrm{t}_{\mathrm{k}}$

b. $\quad *\left[\text { Which argument }\left[\text { that } \mathrm{John}_{\mathrm{i}} \text { is a genius }\right]\right]_{\mathrm{k}}$ did he $\mathrm{i}_{\mathrm{i}}$ believe $\mathrm{t}_{\mathrm{k}}$

Chomsky (1993) follows Lebeaux's (1988) conclusion that adjuncts may be 'late-merged' in the derivation, avoiding a Condition $\mathrm{C}$ violation. Under this approach, in (18a), the $w h$-phrase which argument merges as the object of believe, and then undergoes wh-movement. Only at this stage does the relative that John made merge, acyclically. At no point during the derivation is Condition C violated (as John never c-commands him), and the R-expression contained

\footnotetext{
${ }^{8} \mathrm{I}$ do not commit myself here to the status of Condition $\mathrm{C}$ or where its effects are determined. It is sometimes assumed that Condition C as a syntactic condition can be dispensed with (Chomsky 1982; Reinhart 1983a,b; Grodzinsky and Reinhart 1993; Reinhart and Reuland 1993).

${ }^{9}$ See especially van Riemsdijk and Williams 1981; Freidin 1986; Lebeaux 1988. Sportiche (2006) highlights that speaker judgements show some degree of variation for some putative adjunct/complement asymmetries.
} 
within the relative clause will not be able reconstruct to the base position of the wh-phrase: the sentence is correctly predicted grammatical. This option is not available in (18b) since the clause containing the R-expression is the complement of argument, and so must merge with argument to satisfy its thematic requirements. Hence, John, contained within the complement clause, must also merge before $w h$-movement takes place. Coreference between John and he results in a violation of Condition $\mathrm{C}$, since he c-commands John before wh-movement takes place. When the clause inside the $w h$-phrase is a relative, as in (18a), it is assumed that a choice can in principle be made whether to merge the relative before or after wh-movement. In (18a) we are forced to choose the latter since merging the relative clause before $w h$-movement would induce a Condition $\mathrm{C}$ violation, just as in (18b).

In other cases, the presence of an anaphor within a DP-internal constituent could force a syntactic analysis in which that constituent is merged cyclically (before $w h$-movement), in order to ensure that an anaphor which is not c-commanded by its antecedent in its surface position is c-commanded by it at some earlier stage of the derivation. The grammaticality of (19) confirms that this is possible.

(19) [Which stories about each other $]_{k}$ did the journalists publish $t_{k}$

Suppose, though, that the adjunct also contains an R-expression, which results in a Condition $\mathrm{C}$ violation if the adjunct reconstructs (i.e. is merged before $w h$-movement). Sportiche (2006) suggests that such cases provide evidence of the interaction of Condition A with Condition $\mathrm{C}$, which he argues applies at LF (if not also elsewhere). As predicted, then, (20) is ungrammatical as at LF we must either violate Condition $\mathrm{C}$ (with reconstruction) or Condition A (with latemerger and hence no reconstruction).

(20) *[Which stories about each other's $s_{i}$ characterizations of the typical male viewer $\left.]_{\mathrm{j}}\right]_{\mathrm{k}}$ would he $\mathrm{j}_{\mathrm{j}}$ conclude the journalists $\mathrm{i}_{\mathrm{i}}$ should publish $\mathrm{t}_{\mathrm{k}}$

(Sportiche 2006)

Sportiche contrasts (20) with (21). It appears that when reconstruction for Condition A does not induce a Condition $\mathrm{C}$ violation, the sentence is grammatical: 
[Which stories about each other's $s_{i}$ characterizations of $\left.\operatorname{him}_{j}\right]_{k}$ would the typical male viewer $_{\mathrm{j}}$ conclude the journalists $\mathrm{i}_{\mathrm{i}}$ should publish $\mathrm{t}_{\mathrm{k}}$

(Sportiche 2006)

The difference is explained as follows. In (20), reconstruction of the wh-phrase brings the typical male viewer into a configuration in which it is c-commanded by he, in violation of Condition C. In (21), however, reconstruction brings the pronoun into a configuration in which it is c-commanded by the the typical male viewer. So rather than Condition $\mathrm{C}$ we are dealing with Condition B in (21), which is satisfied since the the typical male viewer is not sufficiently local to the pronoun.

Sportiche appears to assume that that reference to reconstruction possibilities at LF is required in order to explain the Condition A data: some constituent containing the anaphor needs to be reconstructed at LF in order for the anaphor to be locally bound, while this also induces a Condition $\mathrm{C}$ violation at $\mathrm{LF}$, since he then c-commands the typical male viewer. Yet it is not strictly true that a binding theory that applies at LF is directly supported by this data. Presumably, each other's characterizations... must be an argument of stories, and so here there is no possibility for late merger. In (20), then, there will be a stage of the derivation at which he c-commands the typical male viewer. This, it seems, is enough to induce a Condition $\mathrm{C}$ violation in any case, so independently of reconstruction possibilities, (20) must be ruled out, just as (22) is:

$$
\text { *[Which stories about the typical male viewer }]_{\mathrm{k}} \text { does he } \mathrm{i}_{\mathrm{i}} \text { want } \mathrm{t}_{\mathrm{k}} \text { published? }
$$

As is well known (see, e.g., Lebeaux 1998), interpreting an R-expression in a 'high' position cannot save a derivation in which Condition $\mathrm{C}$ was violated before $\mathrm{A}^{\prime}$-movement. ${ }^{10}$ It seems, then, that contra Sportiche, (20) in fact tells us nothing about the interaction of Condition A with Condition $\mathrm{C}$, since it is ruled out for exactly the same reason as an equivalent sentence with no anaphor, like (22): about+DP is not an adjunct, but rather the complement of stories.

\footnotetext{
${ }^{10}$ Though Lebeaux (1998) highlights that A-movement of a constituent containing an R-expression can save a derivation in which the R-expression was previously in a Condition $\mathrm{C}$ configuration; Lebeaux terms this the "hole in Condition C'.
} 
A reviewer notes that it is possible to construct equivalent sentences that involve both an anaphor and an R-expression contained within a complement to the noun, as opposed to within an adjunct. Proposing (23), the reviewer suggests that such cases do exhibit the relevant contrast, predicted by a binding theory that applies at LF:

(23) a. [Which stories [that each other's $\mathrm{s}_{\mathrm{j}}$ friends told him $\left.\left._{\mathrm{i}}\right]\right]_{\mathrm{k}}$ should $\mathrm{John}_{\mathrm{i}}$ assume that his children like $_{\mathrm{k}}$ ?

b. $\quad *\left[\right.$ Which stories [that each other's $\mathrm{j}_{\mathrm{j}}$ friends told $\left.\left.\mathrm{John}_{\mathrm{i}}\right]\right]_{\mathrm{k}}$ should he $\mathrm{i}_{\mathrm{i}}$ assume that his children like $_{\mathrm{k}}$ ?

However, such examples are problematic for reasons independent of any Condition C/Condition A interaction. Reinhart and Reuland (1993), Hornstein (2000), and Hicks (2006) show that reciprocals in certain syntactic positions exhibit properties equivalent to those of nonlocally bound reflexives in English (sometimes termed 'logophors'). Hornstein (2000: 186) and Hicks (2006: 140) provide examples suggesting that reciprocals embedded within the subject of a finite clause exhibit these nonlocal properties. For a number of speakers, nonlocal reflexives and reciprocals are judged as marginal or ungrammatical. Nonlocal reflexives and reciprocals are characterised by not requiring an antecedent that allows Condition A to be satisfied: they are subject to different principles of interpretation. By many binding theories, then, the reciprocal embedded within a subject position is not treated as a locally bound anaphor. A further complication with the evidence provided by (23) for Condition A applying at LF is that the contrast between (23a) and (23b) does not seem to be nearly as sharp as the original contrast presented by Sportiche (2006). In fact, in both (23a) and (23b) I find the reciprocal hard to link to the required antecedent. ${ }^{11}$

\footnotetext{
${ }^{11}$ However, even if the contrast between (23a) and (23b) is robust for some speakers, and even if the reciprocal is of the type that requires local binding, given the modification to anaphor binding proposed in section 4 below, the contrast could still be explained without resorting to a version of Condition A that applies at LF.
} 


\subsection{Quantifier scope interacting with A-movement across an anaphor}

Trapping effects are rather more robustly observed in the interaction of Condition A with quantifier interpretation. As noted by Aoun (1982) and Hornstein (1995) among others, raising a quantifier DP across an unmoved anaphor bound by it results in a trapping effect for the purposes of scope interpretation of the raised DP. ${ }^{12}$ In (24), from Fox (2000: 145), two scope alternations are possible (though $\exists>\forall$ is pragmatically implausible of course, requiring one or more soldiers to each die in more than one battle):

(24) [At least one soldier $]_{i}$ seems (to Napoleon) [ $t_{i}$ to be likely to die in every battle].

$$
\forall>\exists ; \exists>\forall
$$

When the experiencer is an anaphor (or a bound pronoun, as in (25b)), however, the pragmatically plausible inverse scope reading disappears. ${ }^{13}$

(25) a. [At least one soldier $]_{\mathrm{i}}$ seems to himself $\mathrm{i}_{\mathrm{i}}\left[\mathrm{t}_{\mathrm{i}}\right.$ to be likely to die in every battle].

$$
* \forall>\exists ; \exists>\forall
$$

b. $\quad$ At least one soldier $]_{\mathrm{i}}$ seems to his $\mathrm{i}_{\mathrm{i}}$ commanders $\left[\mathrm{t}_{\mathrm{i}}\right.$ to be likely to die in every battle].

$* \forall>\exists ; \exists>\forall$

Unless the anaphor has to be bound by its antecedent at LF, we cannot explain why the inverse scope reading is impossible. Note that narrow-syntactic approaches would not naturally predict this. Presumably, once an anaphor has been linked to its antecedent, the binding relation is established and reconstruction should not be able to tamper with it.

\footnotetext{
${ }^{12}$ Aoun (1982: 31-2, fn.7) attributes this observation to Luigi Rizzi, noting that this provides support for a binding theory which applies at LF, rather than at S-structure.

${ }^{13}$ Lebeaux (1998); Fox (2000); Wurmbrand and Bobaljik (1999) take this as evidence that the inverse scope reading is not derived from long distance Quantifier-Raising of the universal in the embedded clause, since otherwise the trapping effect in (25a) is unexplained.
} 


\section{A modification to the analysis of Condition A effects}

This effect is robust, strikingly, in a way that the data from the supporting arguments for Condition A at LF (below) are not. If we wish to maintain that a narrow-syntactic binding theory is the ideal we must do some work in explaining why LF-positions of the anaphor appear to be relevant. Fox (2000: 146, fn.9) hints that Lebeaux's (1998: 11) conclusion that a single LF representation must be the input to Condition A and quantifier scope interpretation is not necessarily correct. Leaving aside Condition A for a moment, note that exactly the same prediction would arise from simply stating that an anaphor must be c-commanded (regardless of how locally) by its antecedent at LF. Moreover, adopting an LF approach to Condition A of course offers no explanation for the appearance of the trapping effect in (25b), where a bound pronoun appears in the place of the anaphor. Clearly, in order to explain the trapping effect in (25b) we need a constraint independent of the classical binding theory, requiring variables to be in the scope of (i.e. c-commanded by) their binders at LF. Since anaphors are obligatorily bound variables, this constraint will also explain the absence of an inverse scope reading in (25a), independently of Condition A.

I suggest, then, that trapping effects have nothing to do with Condition A, strictly speaking. ${ }^{14}$ Anaphor binding is then governed by two principles:

\section{(26) Constraints governing anaphor binding:}

a. Bound variables must be in the scope of their binder at LF. ${ }^{15}$

b. An anaphor must be bound during narrow syntax by an antecedent which is sufficiently local to it.

\footnotetext{
${ }^{14}$ This possibility has been explored in previous work. Romero (1998) adopts the proposal of an earlier draft of Lebeaux (1998) that i) Condition A must be met at some stage of the derivation, and ii) anaphors must be c-commanded at LF: "anaphor licensing is not just a matter of Principle A but also a matter of scope" (Romero 1998: 356). I do not have access to this draft, but this is clearly not how the argument is presented in Lebeaux (1998), where Condition A is argued to apply at LF.

${ }^{15}$ Here I have chosen 'in the scope of' rather than 'c-commanded by' since as highlighted below, not quite all variable binding appears to involve strict c-command.
} 
For the moment we will refer to the latter as Condition A; its precise formulation need not concern us here. Crucially, (26) makes two different empirical predictions from any LF approach to Condition A:

i) An anaphor will be ungrammatical if not c-commanded by its antecedent both in narrow syntax and at LF.

ii) Local c-command need not hold between an anaphor and its antecedent at LF.

One criticism of the approach to anaphor binding in (26) could be that it introduces a redundancy with respect to c-command. The requirement that the antecedent c-command the anaphor holds both during narrow syntax (due to Condition A) and also at LF (for successful variable binding). While this is perhaps a technical inelegance, there is empirical evidence that the apparent redundancy really should be there: I suggest that this is in fact an advantage over the LF-only view of Condition A. As first noted (to my knowledge) by Reinhart (1976, 1983b), some well-known cases of variable binding do not in fact involve surface c-command. As Hornstein (1995: 118) notes, typically a non-c-commanding quantifier can bind a variable if it is either the subject of a DP or embedded inside an adjunct PP.

(27) a. [[Every girl's $]_{i}$ father $]$ thinks she ${ }_{i}$ 's a genius

(Kayne 1994)

b. [Someone [from every city $\left.y_{i}\right]$ loves $i_{i}$

(Hornstein 1995)

c. [The owner of [every car in the street $\left.]_{\mathrm{i}}\right]_{\text {should move }} \mathrm{it}_{\mathrm{i}}$ on Mondays

(Reuland 1998)

Similarly, other phenomena assumed to require c-command at LF in order to be licensed show the same behaviour, like Negative Polarity Items:

(28) [[No-one's] ticket] will be worth anything if the manager decides to rest all the best players.

We might suppose, then, that in a way that is perhaps not properly understood, ${ }^{16}$ the c-command

${ }^{16}$ See, e.g., Kayne (1994); Hornstein (1995); Reuland (1998) for suggestions. For example, Hornstein 
requirement on certain licensing procedures at LF can be slightly relaxed somehow. Yet it is also well known that the c-command requirement is stricter on anaphors than on bound pronouns: anaphors must be strictly c-commanded by their antecedent.

If both Condition A and the constraint on binding variables simply hold at LF then this fact is unusual: movement of every girl to the edge of the clause should allow it to locally c-command the anaphor, satisfying Condition A if it were to apply at LF. Yet if anaphors on the other hand must be both bound at LF and locally c-commanded by their antecedent during narrow syntax, then we have an explanation for the ungrammaticality of (29).

It should be noted here that Kayne (1994) questions whether the c-command requirement for anaphors really is as strict as it appears. Kayne provides the following examples where the c-commanding DP is not an appropriate antecedent for the anaphor (unlike cases such as (29), which Kayne concedes are ungrammatical). This is supposed to make the sentences somehow more grammatical: ${ }^{17}$

$$
\begin{aligned}
& \text { a. ?[[Every girl's } \left.\left.s_{i}\right] \text { room }\right] \text { contains a picture of herself } f_{i} \\
& \text { b. ?[[Everyone's } \left.s_{i} \text { room }\right] \text { suited himself } f_{i}
\end{aligned}
$$

(1995: 25-26) suggests that the binder for the pronoun undergoes Quantifier Raising (QR) into a position which c-commands the pronoun, rectifying the c-command configuration, which must hold at LF. While this may be plausible to account for some of the data (though apparently not why quantifier DP complements do not show the same behaviour), the particular account adopted is not crucial for the point I wish to make here. See also Hornstein (1995: 118-122) for further possibilities for analysis.

${ }^{17}$ It is not clear to me how exactly the presence of a 'potential antecedent' can be used to determine the grammaticality of the anaphor in terms of a distinction between (29) and (30b). The intuition, as Hornstein (1995) reports, is that every girl's father is closer to the anaphor herself than every girl's, hence the ungrammaticality of (29). On the other hand, everyone's room is not a potential antecedent for the anaphor himself, hence there is less of an interference. But why is it not a potential antecedent? An inanimate DP can of course bind an anaphor, if only itself. Animacy cannot be responsible, so what about a $\phi$-feature mismatch between everyone's room and himself? This cannot be the case either, since this would also rule out (29), where every girl's father and herself mismatch. 
However, it could well be that for speakers who find these sentences acceptable to some degree, the possibility of interpreting the reflexive as a 'logophor' (a type of often stressed reflexive pronoun which does not necessarily require a syntactic antecedent) interferes with the judgments. I believe that this is supported by a significant contrast for many speakers between the relative acceptability of (30a) and (30b). Logophoric reflexives are particularly common in the object position of picture-DPs as in (30a), which is certainly not entirely ungrammatical for me. On the other hand, all native speakers I have consulted find (30b) ungrammatical. I suggest that this is because reflexives as objects of transitive verbs cannot typically be logophors for most speakers, always requiring a local c-commanding antecedent.

\section{Counter-evidence 2: idiom interpretation}

Locality is the key difference between the narrow-syntactic approach to Condition A and an LF approach: the LF approach predicts that local c-command must hold at LF, while the syntactic approach does not. While Lebeaux (1998) concedes that Condition B must apply throughout the derivation rather than at LF, he nevertheless argues strongly against Condition A also applying during the derivation. Lebeaux proposes that a bundle of conditions related to semantic interpretation apply at a single level, LF: quantifier (scope) interpretation, bound pronoun interpretation, Condition A, and idiom interpretation. I have argued above that Condition A should not come under this group, but that the relevant aspect of anaphor binding which should do is subsumed by bound variable interpretation. We have assumed that quantifier interpretation also applies at LF, and seen that evidence from scope trapping effects is at least consistent with my approach. Our attention now turns to the evidence in the literature against it.

\subsection{Subjectless picture-DP idiom chunks}

Chomsky (1993) devises an argument that idiom interpretation is determined by reconstruction at LF to support his assumption that the binding conditions also apply there.

$$
\mathrm{John}_{\mathrm{i}} \text { wondered }\left[\left[\text { which picture of himself } \mathrm{i}_{\mathrm{j} / \mathrm{j}}\right]_{\mathrm{k}} \text { Bill } \mathrm{j}_{\mathrm{j}} \text { took } \mathrm{t}_{\mathrm{k}}\right]
$$

(Chomsky 1993) 
When take pictures has a literal reading (i.e. carrying them away), in previous frameworks it was possible to say that (31) showed that Condition A could be met either at D-structure (with Bill the antecedent) or at S-structure (with John the antecedent). Chomsky's claim is that even if D-structure and S-structure are eliminated, these two readings could instead arise from two different LF representations for (31), i.e. (32a) or (32b):

(32) a. John wondered [which picture of himself] [Bill took which picture of himself]

b. John wondered [which picture of himself] [Bill took which picture of himself]

However, when the predicate take pictures is interpreted idiomatically (i.e. with a camera), the only possible reading is the one where the reflexive is bound by the embedded subject. ${ }^{18}$ Chomsky claims that on the idiomatic reading, take a picture of himself has to be interpreted at LF as a syntactic unit, so reconstruction is forced. So a reconstructed interpretation for the idiom chunk containing the anaphor results in the same type of trapping effect as seen above. We might wonder whether there could be another explanation though. It has been suggested on several occasions (see Lebeaux 1998; Bhatt and Pancheva 2001; Fox and Nissenbaum 2004, and particularly Safir 1999) that there could be syntactic differences between the idiomatic construction and the literal one: it could be that the picture-DP in the idiomatic construction has a PRO subject controlled by the subject of take, as in (33).

$\mathrm{John}_{\mathrm{i}}$ wondered [which $\mathrm{PRO}_{\mathrm{j}}$ picture of himself $\mathrm{j}_{\mathrm{k}}\left[\mathrm{Bill}_{\mathrm{j}}\right.$ took $\left.\mathrm{t}_{\mathrm{k}}\right]$

If so, regardless of any reconstruction of the wh-phrase, it will always contain a PRO which acts as the antecedent of the reflexive. Since PRO must be interpreted as coreferent with the subject of take pictures, this explains why the anaphor in that construction cannot be bound by the matrix subject.

\footnotetext{
${ }^{18}$ Note that Lasnik and Hendrick (2003) are 'unconvinced' that there is a significant contrast in the crucial sentences with the idiomatic and non-idiomatic readings of take pictures.
} 
If (33) is plausible, such cases tell us nothing about whether or not Condition A applies at LF: the binding domain for the anaphor in question is its minimal DP, so the $w h$-movement of that DP is irrelevant to binding. Condition B effects suggest that the PRO analysis is indeed plausible, as the idiomatic take pictures also differs from the literal reading in terms of Condition B. Assume that pronouns have to be free in their minimal DP. On the literal reading of (34a), the grammaticality of the bound reading for the pronoun follows. On the idiomatic reading though, the equivalent interpretation is ungrammatical, only explained as a Condition B violation if a PRO subject is inside the DP, as in (34b). ${ }^{19}$
a. $\mathrm{John}_{\mathrm{i}}$ took [DP several pictures of $\left.\mathrm{him}_{\mathrm{i}}\right]$
b. $* \mathrm{John}_{\mathrm{i}}$ took $\left[\mathrm{DP}\right.$ several $\mathrm{PRO}_{\mathrm{i}}$ pictures of him $\left.{ }_{\mathrm{i}}\right]$

An argument for Condition A at LF from 'creation verbs' (e.g. compose songs and invent jokes) receives a similar explanation. Building on work by Heycock (1995), Fox and Nissenbaum (2004) assume that creation verbs by their very nature require reconstructed LFs when their object $w h$-moves. Since these predicates force reconstruction, if Condition A applies at LF we expect ungrammaticality when the requirements of Condition A and creation verb interpretation clash, i.e where $w h$-phrase reconstruction is obligatory but where Condition A requires the $w h$-phrase that it is embedded in to have the surface interpretation in order to meet locality requirements: ${ }^{20}$

\footnotetext{
${ }^{19}$ Bhatt and Pancheva (2001) suggest that more generally, in cases where a matrix verb's semantics require its agent to corefer with subject of its DP complement, a PRO subject is obligatory. This correctly predicts the following contrast:

(i) $* \mathrm{John}_{\mathrm{i}}$ told $\left.\left[\mathrm{DP}_{\mathrm{PRO}} \mathrm{PR}_{\mathrm{i}} \text { lies about him }\right]_{\mathrm{i}}\right]$

(ii) $\mathrm{John}_{\mathrm{i}}$ heard $\left[\mathrm{DP}\right.$ rumours about $\left.\mathrm{him}_{\mathrm{i}}\right]$

${ }^{20}$ While the judgments seem pretty clear to me, it is worth highlighting that (35a) is extremely odd, implying that ideas are quantifiable, and that the quantity is somehow perceivable. It seems to me that any possible answer like Mary is likely to have four ideas about John would be pragmatically extremely bizarre (for reasons independent of the binding theory).
} 
(35) a. I asked John ${ }_{\mathrm{i}}$ how many ideas about himself $\mathrm{i}_{\mathrm{i}}$ Mary is likely to $\{$ hear about/*have $\}$

b. I asked the boys ${ }_{i}$ how many jokes about each other ${ }_{i}$ Mary is likely to $\{$ retell/*invent $\}$

(Fox and Nissenbaum 2004)

In (35a), have (ideas) is a creation verb, while hear about (ideas) is not; in (35b), invent (jokes) is a creation verb, while retell (ideas) is not. As Fox and Nissenbaum (2004: 479) concede, we might equally assume that creation predicates force a PRO subject in their DP complement. As before, it seems highly plausible that picture-DPs contain a PRO subject when the agent of the picture-noun has to be interpreted as the subject of the predicate which selects it. ${ }^{21}$ This takes away the argument from idiom and creation verb interpretation that Condition A applies at LF.

\subsection{Picture-DP idiom chunks containing subjects}

Lebeaux (1998) claims that in some idiom constructions, no PRO subject analysis will be available, as the position PRO occupies must already be filled:

(36) a. Sue and Bill wondered [how much of each other's minds] $]_{i}$ Mary and John blew $\mathrm{t}_{\mathrm{i}}$

b. It was [DP each other's shoulders $]_{i}$ that the boys said $t_{i}$ that the girls cried on $t_{i}$

c. It was [DP each other's heads $]_{i}$ that John and Mary said $t_{i}$ that Bill and Sue turned $\mathrm{t}_{\mathrm{i}}$

(Lebeaux 1998)

The crucial question is whether the binding of the reciprocal always has to be by the deepest embedded subject, so by Mary and John in (36a), the girls in (36b), and Bill and Sue in (36c). During the derivation, in each sentence the anaphor reaches a position in which it can be bound by the higher antecedent (in the final position in (36a) and in the intermediate trace position in $(36 b) /(36 c))$. Yet idiom interpretation would require the interpretation of the lowest copy

\footnotetext{
${ }^{21}$ I do not commit myself here to a particular theory of PRO interpretation, nor to the stage of the derivation at which PRO interpretation is determined. (Presumably, the choices will be the same as for anaphor binding; narrow syntax or LF.) There are too many (well known) differences between PRO and anaphors for me to suggest here that a narrow-syntactic approach to binding can naturally be extended to accommodate control.
} 
of the DP which contains the anaphor. After reconstruction, the anaphor would remain in the c-command domain of the higher antecedent, while it would only be in the local c-command domain of the lower antecedent. So if Condition A applies at LF, only the lower reading should be possible for the anaphor. But if only bound variable interpretation is required at LF, then the higher reading should remain possible. Lebeaux (1998) claims that in each case only the lower antecedent is possible, supporting his conclusion that Condition A applies at LF. Here I simply disagree with Lebeaux's judgment, and many speakers feel no preference at all for the lower reading over the higher one. If so, and idiom interpretation does require reconstruction, then these sentences provide evidence that only bound variable interpretation (and not Condition A) applies at $\mathrm{LF}^{22}$

\section{Counter-evidence 3: Reconstruction with expletive associates}

Fox and Nissenbaum (2004) look for a different sort of example involving reconstruction, but like Lebeaux, where there can be no suggestion of PRO interfering in the test. They come up with (37):

(37) a. I asked John how many books about him Mary thinks there are in the library

b. I asked John how many books about himself Mary thinks \{are in the library/*there are in the library

In (37b), we have two options in the embedded clause: to use an expletive construction or not. Fox and Nissenbaum assume that in how many questions with an expletive there, reconstruction of the $w h$-phrase is forced, for reasons related to the definiteness restriction on the associate. So by assumption the wh-phrase has to reconstruct to its pre-movement position

\footnotetext{
${ }^{22}$ Alternatively, as David Adger (p.c.) suggests, these predicates are simply not idiomatic in the relevant way and hence do not require reconstruction. This still of course takes away Lebeaux's argument that Condition A applies at LF, but does not then offer particular support for my alternative. Indeed, based on the analysis of certain DPs and their movements at LF proposed by Diesing (1992), Runner (2002) argues that certain constructions involving idioms such as this cannot be assumed to form a complete unit at LF as Chomsky (1993) assumes. See also Sportiche (2006) for further arguments against idiom reconstruction.
} 
in the LF representation. Assuming that reconstruction really is obligatory, my approach to Condition A and the LF-only approach make separate predictions. On the LF-only approach, reconstruction of the $w h$-phrase results in a configuration which is in violation of Condition $\mathrm{A}$, since the anaphor is not sufficiently locally bound. On my approach, no violation follows, since Condition A would be met in narrow-syntax, and reconstruction still leaves the anaphor in a position c-commanded by its antecedent, satisfying the condition on bound variables. So the LF-only approach predicts (37b) to be ungrammatical with the expletive construction, while my approach predicts that there should be no difference between the construction with the expletive and the one without. While Fox and Nissenbaum (2004) claim the judgment for (37b) supports the former, once again the crucial judgment seems highly contentious. I feel that there is simply no contrast whatsoever, a view supported by Uchiumi (2006), whose survey of native speakers found both (37a) and (37b) to be judged within the acceptable range. As Uchiumi concludes, the conclusions that Fox and Nissenbaum draw based on these data fall some way short of being convincing.

\section{Counter-evidence 4: Reconstruction with bound pronouns}

Fox and Nissenbaum (2004) go on to provide an apparently more robust empirical argument for Condition A at LF. This time it comes from the interaction of Condition A with bound variable interpretation of pronouns. The crucial sentence is (38a).

(38) His aides should have explained to President Clinton $_{i} \cdots$

a. *... [what kinds of pictures of himself $f_{i}$ and her ${ }_{j}$ baby] no mother ${ }_{j}$ wants to see

b. ... [what kinds of pictures of himself $f_{i}$ and her ${ }_{j}$ baby] Mrs Jones ${ }_{j}$ wants to see

They assume that the ungrammaticality of the bound reading for the pronoun in (38a) is the result of two contradictory requirements: reconstruction having to apply so that the bound pronoun is c-commanded at LF, but not being able to apply since this would induce a Condition A violation-if, of course, Condition A also applies at LF. In (38b) on the other hand, we are dealing with a coreferential pronoun rather than a bound one and so there is no requirement for 
reconstruction, and Condition $\mathrm{A}$ is met at LF. The problem for the approach to anaphor binding in (26) is that if Condition A applies in narrow syntax, then it is met in (38a) after movement, while reconstruction of the $w h$-phrase still leaves the anaphor in a position c-commanded by its antecedent: the sentence is incorrectly predicted to be grammatical.

The judgments here are not as sharp for me, and I find (38b) less than perfect. Some speakers I have consulted find no contrast, with both sentences being acceptable. Indeed, Uchiumi (2006) reports that some of his consultants judged (38a) as worse than (38b), some judged them the other way around, and some perceived no contrast at all. This high degree of speaker variation in these sentences leads me to suspect that the example might be more complicated than Fox and Nissenbaum assume. As noted above, typically judgments become quite variable when the reflexive in question is logophoric, rather than a locally bound anaphor. It is well known that when a picture-DP has no subject, the reflexive object of the picture-noun may exhibit certain properties suggesting that the reflexive may not be a true anaphor. Therefore in (38), in theory we could be dealing with a logophor, and these are not subject to Condition A. Fox and Nissenbaum concede this much, but claim that logophoric reflexives do not typically take objects as their antecedents. They claim that choosing President Clinton as the object of the matrix clause rather than the subject removes the possibility that we could be dealing with a logophor, and so Condition A really is at stake here. However, things are more complicated still, since logophors can also take non-c-commanding antecedents:

$$
\text { Max's }_{\mathrm{i}} \text { eyes watched eagerly a new picture of himself } f_{\mathrm{i}} \text { in the paper }
$$

(Reinhart and Reuland 1991)

Fox and Nissenbaum apparently fail to notice that in (38) there is another potential antecedent for a logophoric reflexive, namely the pronoun his, which corefers with President Clinton. So what we might have in this sentence is not an anaphor bound by President Clinton but a logophor which takes the pronoun his as an antecedent. To check, we need to eliminate the latter possibility, as in (40). 
(40) The senators should have explained to President Clinton $_{\mathrm{i}} \ldots$
a. ??...[what kinds of pictures of himself $f_{i}$ and her ${ }_{j}$ baby] no mother ${ }_{j}$ wants to see
b. ??...[what kinds of pictures of himself $f_{i}$ and her ${ }_{j}$ baby] Mrs Jones ${ }_{j}$ wants to see

I am not entirely sure of my judgments on these, but it seems to me that $(40 \mathrm{a}, \mathrm{b})$ are to some extent worse than $(38 \mathrm{a}, \mathrm{b})$; certainly, for me the contrast is blurred. The final thing I wish to highlight in connection with these sentences is that very similar cases seem to differ unpredictably in their acceptability. So although (38a) and (41) would be expected to show the same effect, I find (41) considerably better.

??The fathers showed President Clinton $_{\mathrm{i}}$ [which pictures of himself ${ }_{\mathrm{i}}$ holding her $_{\mathrm{j}}$ baby] $_{\mathrm{j}}$ every mother ${ }_{j}$ would want to see.

In short, the fluctuation in speaker judgments and the variation across similar sentences points towards the possibility that the logophoric reflexive is interfering in the crucial contrasts. In fact, Pollard and Sag (1992, 1994); Reinhart and Reuland (1993) and assume that all of the classic connectivity effects in $w$ h-movement constructions are instances of logophoric reflexives. Note that in these cases, objects can also bind picture-DP reflexives in the left-edge of CP, just as subjects can:
(42) a. John $i$ asked Mary which pictures of himself ${ }_{i}$ looked the best
b. John asked Mary $\mathrm{j}_{\mathrm{j}}$ which pictures of herself $\mathrm{j}_{\mathrm{j}}$ looked the best

Under Fox and Nissenbaum's assumptions about subject orientation of logophoric reflexives, this evidence would be taken to support the view that that these are instances of locally bound anaphors. However, this conclusion may be incorrect. First, some speakers simply do not judge these sentences as grammatical, presumably since their grammar does not contain the logophoric reflexive. Second, it appears that pragmatic factors may interfere with the (putative) binding relation between the reflexive in the embedded clause and the antecedent in the matrix clause, which of course is a well-known (if not well-understood) property of logophoric reflex- 
ives. Compare (42a) with (43a) and (42b) with (43b), where the locality relation between the picture-DP reflexive and the subject binder is identical:

(43) a. ??John ${ }_{i}$ asked Mary $\mathrm{j}_{\mathrm{j}}$ which pictures of himself $\mathrm{i}_{\mathrm{i}}$ she $_{\mathrm{j}}$ liked best

b. *?John ${ }_{\mathrm{i}}$ asked Mary $\mathrm{j}_{\mathrm{j}}$ which pictures of herself $\mathrm{j}_{\mathrm{j}} \mathrm{he}_{\mathrm{i}}$ should keep

The possibility of the matrix subject (43a) or object (43b) binding the reflexive is apparently overridden if the $w h$-phrase has moved across an embedded subject coreferent with the matrix object or subject respectively. Presumably this gives the embedded subject (and coreferent matrix argument) some sort of higher discourse prominence, and so the logophoric reflexive is degraded when bound by the less prominent argument. If we were indeed dealing with a true anaphor in such cases, this sort of effect would not be explained at all. Clearly then, such factors make it extremely difficult to be maintain that the original contrast that Fox and Nissenbaum (2004) report for $(38 a, b)$ is significant. Even if it is, the chances are that we are not really testing Condition A effects there in any case.

\section{Conclusion}

When it comes to figuring out where the binding theory applies, the stakes are highest when it comes to Condition A, largely because the evidence for the binding theory applying at LF in the first place is strongest from Condition A effects. For example, Lebeaux (1998), who claims that Condition A applies at LF, nonetheless suggests that Conditions B and C apply during the derivation rather than at LF. We have seen that various interpretive phenomena do not necessarily interact with Condition A in the way that they are often assumed to if Condition A applies at LF. Some interactions between interpretive phenomena and anaphor binding are indeed robustly observed, most notably in scope trapping effects when a quantifier DP is raised across an anaphor bound by it. However, we have shown that the interacting factor with scope is not Condition A (i.e. the requirement that an anaphor be locally c-commanded by its antecedent) but rather an independent constraint that bound variables must be c-commanded at LF by their binders: the same trapping effect is observed with bound pronouns in the place of anaphors. 
At the same time, we have only been able to draw tentative conclusions that a narrowsyntactic version of Condition A makes more successful empirical predictions than the LF approach. However, by no means do the two approaches to Condition A (and indeed, to the binding theory in general) start out on an equal footing. As noted at the outset of the chapter, empirical evidence for a narrow-syntactic Condition B strongly argues against an LF approach, since its effects can be influenced by elements which cannot be present in LF representations: we have seen various examples cross-linguistically showing that Condition B interacts with Case features of pronouns, verbal agreement, and phonological factors. Importantly, theoretical concerns also lead us to strongly favour a narrow-syntactic approach, in particular because it allows us to determine locality effects uniquely by syntactic factors, and allows more promising avenues for capturing crosslinguistic variation. Building on the findings of recent research (Hornstein 2000; Kayne 2002; Zwart 2002, 2006; Hicks 2006), a possible reduction of the binding conditions to independent syntactic operations provides scope for a complete elimination of the binding theory, and so the Minimalist ideal is within sight.

\section{References}

Aoun, J. (1982). On the logical nature of the binding principles: Quantifier lowering, double raising of 'there', and the notion empty element. The Proceedings of the North East Linguistic Society 12, 16-35.

Belletti, A. and L. Rizzi (1988). Psych-verbs and theta-theory. Natural Language and Linguistic Theory 6, 291-352.

Bhatt, R. and R. Pancheva (2001). Implicit arguments. Ms., University of Texas, Austin and USC.

Boeckx, C. (2001). Scope reconstruction and A-movement. Natural Language and Linguistic Theory 19(3), 503-548.

Chomsky, N. (1973). Conditions on transformations. In S. A. Anderson and P. Kiparsky (Eds.), A Festschrift for Morris Halle, pp. 232-285. New York: Holt, Rinehart and Winston. 
Chomsky, N. (1981). Lectures on Government and Binding. Dordrecht: Foris.

Chomsky, N. (1982). Some Concepts and Consequences of the Theory of Government and Binding. Cambridge, MA: MIT Press.

Chomsky, N. (1986). Knowledge of Language: Its Nature, Origin and Use. New York: Praeger.

Chomsky, N. (1993). A minimalist program for linguistic theory. In K. Hale and S. J. Keyser (Eds.), The View from Building 20: Essays in Linguistics in Honor of Sylvain Bromberger, pp. 1-52. Cambridge, MA: MIT Press. Reprinted as chapter 3 of Chomsky (1995c), 167217.

Chomsky, N. (1995a). Bare phrase structure. In G. Webelhuth (Ed.), Government and Binding Theory and the Minimalist Program, pp. 383-439. Oxford: Blackwell.

Chomsky, N. (1995b). Categories and transformations. In The Minimalist Program, pp. 219394. Cambridge, MA: MIT Press. [= chapter 4 of Chomsky (1995c)]. Based on the shorter article Chomsky (1995a).

Chomsky, N. (1995c). The Minimalist Program. Cambridge, MA: MIT Press.

Chomsky, N. (2000). Minimalist inquiries: the framework. In R. Martin, D. Michaels, and J. Uriagereka (Eds.), Step by Step: Essays on Minimalist Syntax in Honor of Howard Lasnik, pp. 89-155. Cambridge, MA: MIT Press.

Chomsky, N. and H. Lasnik (1993). The theory of principles and parameters. In J. Jacobs, A. von Stechow, W. Sternefeld, and T. Vennemann (Eds.), Syntax: An International Handbook of Contemporary Research, Vol. 1, pp. 506-569. Berlin: Walter de Gruyter. Reprinted as chapter 1 of Chomsky (1995c), 13-127.

Diesing, M. (1992). Indefinites. Cambridge, MA: MIT Press.

Epstein, S., E. M. Groat, R. Kawashima, and H. Kitahara (1998). A Derivational Approach to Syntactic Relations. Oxford: Oxford University Press. 
Epstein, S. D. and T. D. Seely (1999). Against the GF-notion 'subject': Eliminating the EPP and successive cyclic A-movement. Ms., Michigan University and Michigan State University.

Fiengo, R. and J. Higginbotham (1981). Opacity in NP. Linguistic Analysis 7(4), 395-421.

Fox, D. (1999). Reconstruction, binding theory, and the interpretation of chains. Linguistic Inquiry 30(2), 157-196.

Fox, D. (2000). Economy and Semantic Interpretation. Cambridge, MA: MIT Press.

Fox, D. and J. Nissenbaum (2004). Condition A and scope reconstruction. Linguistic Inquiry 35(3), 475-485.

Freidin, R. (1986). Fundamental issues in the theory of binding. In B. Lust (Ed.), Studies in the Acquisition of Anaphora, pp. 151-188. Dordrecht: Reidel.

Grodzinsky, Y. and T. Reinhart (1993). The innateness of binding and of coreference. Linguistic Inquiry 24(1), 69-101.

Hellan, L. (1988). Anaphora in Norwegian and the Theory of Grammar. Dordrecht: Foris.

Hestvik, A. (1990). LF Movement of Pronouns and the Computation of Binding Domains. Ph. D. thesis, Brandeis University, Waltham, MA.

Heycock, C. (1995). Asymmetries in reconstruction. Linguistic Inquiry 26(4), 547-570.

Hicks, G. (2006). The Derivation of Anaphoric Relations. Ph. D. thesis, University of York.

Hoekstra, J. (1994). Pronouns and case: On the distribution of Frisian harren and se 'them'. Leuvense Bijdragen 83, 47-65.

Hornstein, N. (1995). Logical Form: from GB to Minimalism. Oxford: Blackwell.

Hornstein, N. (2000). Move! A Minimalist Theory of Construal. Oxford: Blackwell.

Hornstein, N. (2006). Pronouns in a minimalist setting. University of Maryland Working Papers in Linguistics 14, 47-80. 
Kayne, R. S. (1994). The Antisymmetry of Syntax. Cambridge, MA: MIT Press.

Kayne, R. S. (2002). Pronouns and their antecedents. In S. D. Epstein and T. D. Seely (Eds.), Derivation and Explanation in the Minimalist Program, pp. 133-166. Oxford: Blackwell.

Lasnik, H. (1999). Chains of arguments. In S. D. Epstein and N. Hornstein (Eds.), Working Minimalism, pp. 189-215. Cambridge, MA: MIT Press. Reprinted in Lasnik (2003), 139157.

Lasnik, H. (2003). Minimalist Investigations in Linguistic Theory. London: Routledge.

Lasnik, H. and R. Hendrick (2003). Steps toward a minimal theory of anaphora. In R. Hendrick (Ed.), Minimal Syntax, pp. 124-151. Oxford: Blackwell.

Lebeaux, D. (1988). Language Acquisition and the Form of the Grammar. Ph. D. thesis, University of Massachussetts, Amherst, MA.

Lebeaux, D. (1998). Where does the binding theory apply? Technical Report 98-044, NEC Research Institute, Princeton.

Pollard, C. and I. Sag (1992). Anaphors in English and the scope of binding theory. Linguistic Inquiry 23(2), 261-303.

Pollard, C. and I. Sag (1994). Head-Driven Phrase Structure Grammar. Chicago: University of Chicago Press.

Reinhart, T. (1976). The Syntactic Domain of Anaphora. Ph. D. thesis, MIT, Cambridge, MA.

Reinhart, T. (1983a). Anaphora and Semantic Interpretation. London: Croom Helm.

Reinhart, T. (1983b). Coreference and bound anaphora: A restatement of the anaphora questions. Linguistics and Philosophy 6, 47-88.

Reinhart, T. and E. Reuland (1991). Anaphors and logophors: an argument structure perspective. In J. Koster and E. Reuland (Eds.), Long-Distance Anaphora, pp. 283-321. Cambridge: Cambridge University Press. 
Reinhart, T. and E. Reuland (1993). Reflexivity. Linguistic Inquiry 24(4), 657-720.

Reuland, E. (1998). Structural conditions on chains and binding. In P. N. Tamanji and K. Kusumoto (Eds.), The Proceedings of the North East Linguistic Society 28, pp. 341-356. Amherst, MA: University of Massachusetts, GLSA Publications.

Reuland, E. (2001). Primitives of binding. Linguistic Inquiry 32(3), 439-492.

Reuland, E. (2006). Agreeing to bind. In H. Broekhuis, N. Corver, R. Huybregts, U. Kleinhenz, and J. Koster (Eds.), Organizing Grammar: Linguistic Studies in Honor of Henk van Riemsdijk, pp. 505-513. Berlin: Mouton de Gruyter.

Reuland, E. and M. Everaert (2001). Deconstructing binding. In M. R. Baltin and C. Collins (Eds.), The Handbook of Contemporary Syntactic Theory, pp. 634-669. Oxford: Blackwell.

Romero, M. (1998). The correlation between scope reconstruction and connectivity effects. In E. Curtis, J. Lyle, and G. Webster (Eds.), The Proceedings of the Sixteenth West Coast Conference on Formal Linguistics, pp. 351-365. Stanford, CA: CSLI.

Runner, J. (2002). When minimalism isn't enough: An argument for argument structure. Linguistic Inquiry 33(1), 172-182.

Safir, K. (1999). Vehicle change and reconstruction in A-chains. Linguistic Inquiry 30(4), $587-620$.

Sportiche, D. (2006). Reconstruction, binding, and scope. In M. Everaert and H. van Riemsdijk (Eds.), The Blackwell Companion to Syntax: Volume IV, pp. 35-93. Oxford: Blackwell.

Taraldsen, K. T. (1995). On agreement and nominative objects in Icelandic. In H. Haider, S. Olsen, and S. Vikner (Eds.), Studies in Comparative Germanic Syntax, pp. 307-327. Dordrecht: Kluwer.

Taraldsen, K. T. (1996). Reflexives, pronouns and subject/verb agreement in Icelandic and Faroese. In J. Black and V. Motapanyane (Eds.), Microparametric Syntax and Dialect Variation, pp. 189-211. Amsterdam: John Benjamins. 
Thráinsson, H. (1979). Complementation in Icelandic. New York: Garland.

Uchiumi, T. (2006). Binding and Control: A Unified Approach. Unpublished thesis, McGill University.

van Riemsdijk, H. and E. Williams (1981). NP-Structure. The Linguistic Review 1, 171-217.

Wurmbrand, S. and J. D. Bobaljik (1999). Modals, raising and A-reconstruction. Paper presented at the University of Leiden, October 1999.

Zwart, J.-W. (2002). Issues relating to a derivational theory of binding. In S. D. Epstein and T. D. Seely (Eds.), Derivation and Explanation in the Minimalist Program, pp. 269-304. Oxford: Blackwell.

Zwart, J.-W. (2006). Baker's generalization in a derivational theory of binding. Ms., University of Groningen.

Glyn Hicks

Department of Modern Languages

Avenue campus

The University of Southampton

SO17 1BJ

United Kingdom

Glyn.Hicks@soton.ac.uk 